\title{
Factors influencing the uptake of household water connections in peri-urban Maputo, Mozambique
}

\author{
Ruben Jimenez-Redal ${ }^{\text {a, }}{ }^{1}$, Alison Parker ${ }^{\text {a }}$, Paul Jeffrey $^{a}$ \\ ${ }^{a}$ Cranfield Water Science Institute, Cranfield University, Cranfield, Bedfordshire MK 430AL, \\ United Kingdom \\ E: ruben.jimenez@ehu.es E: a.parker@cranfield.ac.uk E: p.j.jeffrey@cranfield.ac.uk \\ * Corresponding author.
}

\begin{abstract}
Rapid urbanization in many African cities has had a significant impact on the basic water services in peri-urban areas, where providing services can be complex. In the city of Maputo, Mozambique, the initial uptake of new household connections following network construction in peri-urban areas was slow. Focus group discussions with residents and interviews with key actors revealed the importance of offering flexible payment options to the urban poor in order to increase the affordability of connection charges. Although the high connection fee was a constraint, residents were willing to pay if the charges were spread across several monthly instalments. These findings suggest that flexible payment arrangements for customers can both bring utility services within reach of low income households and expand the customer base for utility service providers.
\end{abstract}

\section{Keywords}

Household connections, water supply, peri-urban areas, Mozambique

\section{Introduction}

The world is rapidly urbanizing. Since 2008, the share of the global population living in urban areas has been higher than that in rural ones (UNHabitat 2010). This trend drives a new urgency in the dynamics of providing access to improved water sources because the challenges faced in urban context differ substantially from those in rural conditions. One of the main obstacles to serve safe water in the world's bulging cities is the difficult access to distribution networks in the slums. The challenges that the peri-urban areas of many African cities face in

\footnotetext{
${ }^{1}$ Present address: Faculty of Engineering, UPV-EHU University of The Basque Country, Plaza Europa 1, 20018 San Sebastian, Spain. Tel.: +34659148431

E-mail address: ruben.jimenez@ehu.es (R. Jimenez-Redal).
} 
regard to water service is not only of technical nature but also social and financial. Water utilities are often formally charged with providing $100 \%$ water supply coverage but they find enormous constraints when reaching the slums. Geographical conditions, low ability to pay and the lack of strong local political structures are some of the challenges that water providers often face in the slums.

Many low-and-medium-income countries have been unable to match investments in urban infrastructures with rapid urban growth (Keener et al. 2010). This mismatch has led to a slow down and in some cases a complete halt in the expansion of service delivery to informal settlement areas. The consequence is that a great number of residents from unplanned settlements lack access to basic services such as water supply (Gulyani et al. 2010). Aware of this situation, development agencies have recognised the need to support many cities in their efforts to upgrade urban slum areas, and some programs such as The Cities Alliance have been launched by the World Bank and UN-Habitat focusing on slum upgrading (Goether 2001).

The primary reason for the slow expansion of urban infrastructure into peri-urban slums is the high cost of network extension which has forced many governments to be selective about which areas receive networked services (Ferguson et al. 2003). Local authorities have only been able to afford to expand service delivery to a very small number of urban slum areas, resulting in a limited proportion of the population being served. In this context the process of scaling up service interventions has become a strategic approach for many development agencies in order to ensure appreciable impacts. Related literature reports that a second common reason for failure to undertake service expansion to peri-urban slum areas lies in a lack of political will (Davis 2004). Whilst funding and political ambition are recognised as being of paramount importance in facilitating network expansion, they are not the only bottlenecks. Even when political commitment is guaranteed or when funds are sufficient to meet demands, there are other factors that need to be approached carefully. In particular, attention has been drawn to the need for community priorities to be incorporated into water supply plans through collaboration with utility providers (Allen et al. 2006). Such collaborative approaches can be achieved by developing mechanisms which promote social organisational capacity. In this context, the capacity of the utility in to elicit, understand, and incorporate social needs into its service plans is crucial (Pinera et al. 2009). An appropriate leadership function able to coordinate multiple contributions is also seen as crucial for achieving practical action and NGOs have been suggested as appropriate providers of this function due to their legitimised relationships with stakeholders (Pinera et al. 2009). Finally, slum dwellers' own organisations (formal or informal) constitute a representational and often highly democratic body whose engagement has been found to be important in delivering effective water provision schemes (Burra 2005).

Many of the reported studies in this field are based strongly on scheme implementation experiences and they suggest that users' priorities (Gulyani et al. 2007) and a better understanding of the services they are willing to contribute towards (Raje et al. 2002) need to play a significant role. It is something of a truism that the challenges faced by residents in deprived areas vary considerably from suburb to suburb and that there is no single response appropriate to all cases (Pinera et al. 2009), but calls for interventions to be adapted to particular local conditions (Gulyani et al. 2010) are genuinely challenging to implement. The 
level of heterogeneity even within a single neighbourhood can be extensive (Gessler et al. 2008) with significant variation in income, housing condition, culture, and capacity to take advantage of service provision (Gulyani et al. 2010).

On the supply side of the equation the challenges are no less daunting. Despite the enormous social and economic benefits of providing improved water to the poor, delivering these benefits place significant pressures on utilities (Banerjee et al. 2010). Water providers have to find a balance between the investment required for network expansion and service affordability. Complementing an iterative expansion strategy with carefully targeted subsidies and evolving regulation has been suggested as a way forward (Fernandez-Maldonado 2008) that has a move towards cost reflective tariffs for conventional customers while offering creative options to the poor in order to facilitate services to all (Gerlach et al. 2010). Without such pro-poor policies and sensitive regulatory structures to facilitate them, the urban poor are likely to have to pay very high prices for small quantities of water of uncertain quality from alternative suppliers (Gerlach et al. 2010). There is something of a vicious circle here in that whilst urban water utilities fail to serve low income households because of the high cost involved in extending services to low income settlements, low ability to pay for the connections and low ability to pay the volumetric water rates (Kayaga et al. 2007), such households cannot benefit from cross subsidies in the tariff structure since they are not connected to the piped water supply (Kayaga et al. 2003). Moreover, households that have no water piped to their home often have some members spending one or two hours each day getting water, queuing and filling water containers (UN-Habitat 2003). This represents an extra burden because the time spent in these tasks cannot be employed in income generating activities.

Water providers typically only move to supply unplanned peri urban areas with water services when they are obliged to by contractual commitments. However, even supplying trunk mains through slum neighbourhoods often falls short of service requirements as households are often unable to effect a connection (Kayaga et al. 2007) . Payment is again the issue here as connection costs are usually unaffordable and residents with irregular incomes struggle to pay lump-sum accumulative amounts through regular payments (Malizani 2008). Although there has been much debate about issues such as affordability, willingness to pay and tariff structures in low income areas, most of these discussions have focused on the volumetric consumption charges rather than connection charges (Kayaga et al. 2007). Flexible payment options remain an area of challenge for utilities (Kooy et al. 2008) as do innovative tariff structures and minimum consumption charges which often represent a burden for the poorest customers (Banerjee et al. 2010).

One such city where water services do not extend to all of the poorest citizens is Maputo, the capital of Mozambique. The city is characterized by a developed central area surrounded by densely populated and informally laid out shantytown areas inhabited by the poor. These densely populated areas have been formed around the city centre because that is where the work opportunities arise and where street vendors can find customers. The households are relatively well established, most with block built houses but generally lacking legal property rights. Further out from the city centre the density of population decreases, with some of these outlying areas formally laid out and others less so. Areas which are formally laid out are more likely to be catered for by local service providers without external help. The water supply to the central area and surrounding shantytown areas have was let as concession to a private water company operator called Aguas de Mozambique (AdeM) until 2010. From 2011, though, 
the water utility in charge of serving such population is Aguas da Regiao de Maputo (AdaRM). Both inside and outside this concession area water is also supplied from boreholes operated by SSIPs (Small Scale Independent Providers). Other stakeholders include the Maputo Municipality and FIPAG, the asset holding body for water resources in large cities in Mozambique.

In terms of employment it is estimated that around 60 per cent of the Maputo workforce is engaged in the informal sector where predominant activities are commercial and service provision, with a relative lack of small scale producers of goods (Jenkins 2000).

For administrative purposes the city is divided into units called Bairros, which, at the same time, are subdivided into Quarters. These bairros also host Community Based Organisations (CBOs) that focus on social issues and help residents to coordinate efforts. An example of such CBO is the case of OPTAR, which was founded in 2001 after the disastrous effects of the floods that year, and which has been responding to the bairro's demands ever since. OPTAR has been introduced into the project to act as interlink between the implementers and the community since they can deal with local structures and local residents from within.

Table 1 shows the Poverty Headcount Index within several bairros of Maputo. It represents the proportion of the population living below the poverty line, defined as the monetary value of the basic consumption needs considered to be adequate to reach a certain minimum living standard (Ravallion et al. 2005; Van den Boom 2011). It shows that poverty is not evenly distributed. Maputo Municipality and FIPAG decided to target tertiary network extension into some of the poorest bairros in Maputo, starting from Maxaquene $A$ and $B$, which are among the poorest This was supported by the not-for-profit company Water and Sanitation for the Urban poor (WSUP). These bairros are in the densely populated and informally laid out areas.

The network extension allowed the majority of households in Maxaquene $A$ and $B$ to undertake private connections in an easy way as the distance to the main water pipe was shortened. However, table 2 shows that only $25 \%$ of the households of Maxaquene A and $11 \%$ of Maxaquene B purchased household connections, the remainder opting to buy water from neighbours or water kiosks with a small proportion still purchasing water from other private networks. Small scale individual providers have been operating in underserved districts of Maputo since early 80s but were widely spread in the last decade (Matsinhe et al. 2008) . A detailed analysis undertaken in greater Maputo in 2006 concluded that more people depended on standpipes and water resold than on private household connection (Keener et al. 2010) (see table 4).

This research aims to explain why the take up of household connections was so low.

\section{Methodology}


This research is based upon an inductive research strategy where data collection is a combination of interviews, focus group discussions and direct observation carried out during the months from July to September 2010 plus documentary analysis based on reports published from 2008 to 2011. The research activities are summarised in table 3.

The aim of the focus group discussions was to understand the motivations and barriers to obtaining a household water connection. Participants were selected by purposive non random sampling in order to gather information from specific groups: female with household water connections, female without connection, male with and without connections, CBO members and community representatives, so in total there were five focus groups of ten members each in each bairros. The results were recorded regarding the decisions accepted by the majority of the group. The focus group discussions were conducted at community public premises.

The interview data was supplemented by information from key informants on their understanding as to why the take up of household connections had been so low. Key informants included one local representative from each of the following organisations in each bairros, so ten interviews in total:

- WSUP

- optAR

- AdeM

- Bairros administration

- Quarter administration

The interviews were conducted in a semi-structured way with closed- and open-ended questions. Each respondent was informed about the confidentially, consent and anonymity of provided data according to the authorization from the Cranfield University Science and Engineering Research Ethics Committee.

The data was analysed using comparative and thematic content techniques (Robson 2002). In doing so, opinions and ideas from all the respondents have been organised according to relevant categories. The selection of each category responded to the main themes proposed in related literature to explain uptake of household connections, these included the cost of connection (Collignon et al. 2000; Kayaga et al. 2007), the service reliability (Matsinhe et al. 2008), the alternative sources (Keener et al. 2010), the water quality (Gulyani et al. 2010), the flexibility offered (Allen et al. 2006), the communication process (Gerlach et al. 2010), and the participatory system (Kooy et al. 2008; Fernandez-Maldonado 2008) among others. Once the arguments were organised, the criteria to establish priorities has emerged from the emphasis that informants attributed to each category.

\section{Results and discussion}




\subsection{Flexible payment options}

It is often challenging for water utilities in Africa to balance the efforts of providing safe and affordable water to consumers while ensuring institutional and commercial sustainability of the water system (Banerjee et al. 2010). Many providers fail to serve the urban poor because of the high costs involved in extending services to slum areas due to low ability of slum dwellers to pay for volumetric water rates and connections (Kayaga et al. 2007). In the suburbs of Maxaquene A and Maxaquene B these limitations were only a small part of the problem, in fact the members of nine out of ten focus groups from the study confirmed that they were willing to pay for both volumetric water rates and connection charges. Moreover all of the focus groups identified household connections' volumetric rates as cheaper than those charged by informal providers. This is backed up by the following figures: the official tariff has been established by The Water Regulatory Council (Conselho de Regulaçao do Abastecimento de Agua, CRA) at $22 \mathrm{MT} / \mathrm{m}^{3}\left(0.59 \$ / \mathrm{m}^{3}\right)$ (1 US dollar = 37 Meticais for August 2010) whereas the key informants calculated that average tariff for alternative supplies runs from $50-60$ $\mathrm{MT} / \mathrm{m}^{3}\left(1.35-1.62 \$ / \mathrm{m}^{3}\right)$ for standpipe supplies to $75-80 \mathrm{MT} / \mathrm{m}^{3}\left(2.02-2.16 \$ / \mathrm{m}^{3}\right)$ for neighbour resell. Kayaga and Franceys (2007) found that volumetric consumption charges have often been an obstacle for new users to join the network. In Maxaquene $A$ and Maxaquene $B$ volumetric consumption tariffs are not a significant factor influencing the low number of private connections undertaken following construction of the network, instead the costs of connecting to the water scheme had an impact. This cost covered the meter installation and the cost of material. As it has been recognised by Banerjee and Foster (2010) connection charges have often been a considerable barrier to consumers, but unlike the tariffs they have not received sufficient attention yet. Private connections are often inaccessible to low income residents because the costs of connecting tend to be so high that they are unaffordable for slum dwellers (Malizani 2008). In peri-urban Maputo the connection charge had been established by the water utility in $4400 \mathrm{MT}$ (\$119), which is relatively high comparing with the broad spectrum of connection charges across Africa where it ranges from $\$ 6$ in Sudan to $\$ 240$ in Niger (Banerjee et al. 2010). Members of nine out of ten focus groups remarked that despite their willingness to pay the connection charge of 4400 MT (\$119) they had low ability to do it in the form that it was offered as 4 monthly instalments of 1100 MT $(\$ 29.75)$ each. This explains why only 1437 connections had been undertaken in both suburbs following construction of the tertiary network despite the high number of households (3309) who submitted applications to demonstrate they were interested in joining the scheme (see table 4).

Most low income earners in these areas do not work in salaried positions thus they are obliged to manage their money in a day-to-day basis in irregular terms (Collignon et al. 2000). For the others, those residents who receive a regular salary, normally from the government, key informants have calculated that on average the wages amount between $2250 \mathrm{MT}(\$ 60.81)$ and 3000 MT per month (\$81.08). Normally all the family members pool their income together in order to collectively afford household expenses such as rent, services, school, food and medicines. Slum household are unable to build up any reasonable level of capital to invest in a lump-sum payment normally demanded as connection charge (Kayaga et al. 2007). For this 
reason eight out of ten focus groups highlighted the need to be offered a more flexible payment option. The most accepted proposal by the population consisted of splitting the total charges into 10 monthly instalments of 440 MT (\$11.89) each, which seemed an affordable amount for members of seven out of ten focus groups This proposal is closely related to the recommendations by (Ndokosho et al. 2007) about the need to offer affordable connection fees in order to expand services to new customers. It is also necessary for water providers to learn from mobile phone operators who have been able to segment their customer base and to differentiate their service to cater for all types of customers (Kayaga and Franceys 2007). Water utilities need to allow greater flexibility in order to increase the attractiveness of the project to communities (Davis 2004). In Maxaquene A and Maxaquene B it is understandable why so many people expressed interest in the scheme by submitting applications but in the end were not able to connect because the instalments represented half their month income. Negotiations between the utility and the community had already been successful in slums in other countries, for example in the city of Buenos Aires where a high connection charge was reduced with payment of that amount amortised over several years which resulted on the increase of take-up of network private connections(Kayaga et al. 2007).

Residents in peri-urban Maputo who were not served by the main operator found access to water from formal and informal sources, in the form of public and private kiosks and in the form of water sold on by neighbours. However, residents were dissatisfied with this service and 9 out of 10 focus groups expressed their preference for private household connections, once the obstacle of the connection fee could be overtaken. The reasons they gave to support their preference included the volumetric rate, distance, water quality, service reliability and regulation.

Nine focus groups indicated that they prefer a private connection rather than fetching water from a standpipe or buying from the neighbours since utility rates are lower in volumetric terms. For example, the prices in 2006 were estimated by The World Bank at $11.3 \mathrm{MT} / \mathrm{m}^{3}$ for utility connections, 16.6 for public kiosks, 22.3 for private kiosk and 20.6 for neighbour tap water resell (Keener et al. 2010). Focus groups confirmed that in some cases vendors even charged them twice the price of the fee from a private connection. Often household water resellers charge at a cost that covers the volume sold, their own consumption and gives them an extra little income. The one focus group who said they didn't want a private connection cited a fear of going into debt as their reason.

Seven out of ten groups said that the distance they have to walk to collect water is a major issue since some kiosks are more than $1 \mathrm{~km}$ away from their homes which force them to spend long time fetching water. This represents a constraint for potential income generating activities. While access to water is inexpensive and easy for those with private connections, it becomes a demanding task when water collection requires time, physical energy and opportunity costs (Aiga et al. 2002).

None of the male groups but three out of five female groups also valued service reliability and that is why they prefer household connections. These respondents believe that kiosks are more likely to fail in their service while household connections are more reliable. In these bairros, the responsibility of ensuring that households are provided with enough water has 
traditionally rested on women's shoulders. Thus, female groups are more concerned about water service reliability than men are. If the source where they fetch water fails, it is the women who commit to bringing water from another source no matter how far it is.

Six out of ten focus groups have remarked that water quality is also an important issue when selecting a source. For them higher quality water tastes better, so water from private connections tastessuperior to that from private kiosks which exploit groundwater boreholes and tastes more saline. All five female groups emphasized the importance of water quality while only one out of the male groups paid attention to this factor. Again it is the women who are in charge of finding alternative sources where the water quality is acceptable to the household members, so they consider this factor more important.

Regarding regulation three out of ten groups claim that they do not prefer water resold from their neighbours because it is illegal. This informal service has experienced an unplanned growth, where households with connections have responded to their neighbours' requests to sell water in small quantities. The problem is that this practice is unregulated thus consumers have to buy water early in the morning, around $5.00 \mathrm{am}$, to avoid being penalised by controlling authorities. There is a popular call to make this practice authorized and regulated.

\subsection{Engagement of the Provider}

A slow rate of expansion of services often occurs as the result of a mismatch between the bundle of services offered by the utilities and the priorities of slum households (Davis 2004). If water managers do not effectively take into account the needs of poor residents, disincentives arise for the utility to connect poor household and for poor households to connect the network (Kooy et al. 2008). Utilities need to gain a deeper understanding of the customer's needs and the factors influencing customer satisfaction and loyalty. This can be achieved by enhancing the information flow between utilities and key stakeholders. In Maxaquene $A$ and Maxaquene $B$ nine out of ten focus groups reported that there was a deficient communication between the utility and the community.

Effective service delivery to poor neighbourhoods can require the skills of social intermediation professionals who can facilitate communication between households and service providers (Davis 2004). Important steps in this process include transparent partnerships (Mara et al. 2008) and community mobilisation through the formation of Community Based Organisations CBOs (DelwarAkbar et al. 2007). In peri-urban Maputo the communication between the provider and the population experienced a tremendous improvement since Optar and Kutenga, the community based organisations in Maxaquene $A$ and Maxaquene $B$, started participating in the program. The water utility did not have initially enough resources to communicate thoroughly with the community in the slums and thus the two $\mathrm{CBO}$ s were contracted to undertake such task. The results were very satisfactory to the beneficiaries since the $\mathrm{CBO}$ s were introduced because their role emerged a critical need of the 
community that had not been addressed yet. Optar and Kutenga worked full time every day within the population providing information, attending to demands and responding to queries. As a consequence a bond of trust naturally aroused which allowed the community to receive information in an accessible way and to communicate its needs freely. All focus groups confirmed that Optar and Kutenga were responsible for effective communication in Maxaquene $A$ and $B$ and, what is even more important, that population trusted them. Both CBOs focused on implementing community marketing programmes with the aim of helping housholders to connect. They drew attention to the community's demands and collaborated with the community to meet those demands by organizing group meetings or even visits doorto-door and by transferring information to local district authorities and water utility representatives. As a result the community felt more confident to express its needs and was also motivated to invest in services that satisfied its demands.

The role of the $\mathrm{CBO}$ was also crucial to promote participation in decision making. 8 out of 10 focus groups were not satisfied in the past with the level of community participation in decision making and were willing to negotiate with the utility new mechanisms to incorporate more community members' opinions in the process. For this purpose the work of CBO was necessary to seek a major involvement of the community through meetings, round tables and even door to door campaigns. As Khan and Gerrard (2006) point out, the communication process needs to begin long before project planning starts and continue throughout the life of the project in order to maximise trust between water organisations and stakeholders.

Moreover, stakeholder participation must be ensured through proper effective communication and not just information dissemination (Marimbe et al. 2003). CBO members fit adequately into these tasks because communication entails a dialogue and exchange of ideas and viewpoints that $\mathrm{CBO}$ s have been long encouraging and because $\mathrm{CBO}$ members have been able to build such trust working with the community day after day.

Key informants from both the water utility and WSUP highlighted the need to focus on ongoing capacity building in order to optimize the resources and expertise that CBOs can contribute to the community. Eight out of ten focus groups reported that more sensitization about the water services offered and how to connect to them whereas six out of ten focus groups considered that even more CBO members were needed in order to improve communication. Considering that over time communities alter, people move into and area or leave it and that many variables within a slum may be subject to change, then communication process has to be embraced as an on-going activity emerging from within the community (Khan et al. 2006).

\subsection{Outcome of changes to network extension programme}

Since the focus groups and interviews took place, the fee for a private household connection to the water network was reduced up to $\$ 70$, and what is even more important, the payment of this charge was split into 14 instalments, $30 \%$ of the charge immediately after connection and then, 13 monthly instalments for the remaining amount (Mugabe et al. 2011). This resulted in increasing the uptake of household connections and in just eight months, by August 2011, the number of families served by private connections was estimated as 2732 ( 
$80 \%$ ) in Maxaquene A and 2101 (40\%) in Maxaquene B (see table 4). This confirms the findings of this research, that reducing the connection fee and spreading the payments further meant that more households could get a connection.

However, it is important to consider the need to support vulnerable groups who have no means to afford a connection charge no matter the size of monthly instalments. Key informants from WSUP who have perceived the inequality in access to private water connections resulting from the billing system recommend setting up programs of targeted subsidies from external donors for those destitute groups living under the threshold of extreme poverty, defined as a severe deprivation of basic human needs and quantified by the World Bank as an average daily income of $\$ 1.25$ or less. Such subsidies should cover part of the connection charge.

At the time the data collection for this research was undertaken in 2010 the service provider AdeM was involved in active negotiations with the water regulatory council CRA in order to find an effective solution for the controversial issue of water resale to neighbours. This practice was common among residents of low income districts despite being illegal under the local regulatory framework. By the end of 2011, after fruitful negotiations, the water utility AdaRM and CRA were able to offer contract modalities that allow groups of families to club together for a single connection (Mugabe et al. 2011). This represents a new model of supplying water to underserved poor residents of Maputo in accordance with the new paradigm of water supply described by Mara and Alabaster (2008) which promotes water supply in urban areas to groups of households instead of individual households in order to achieve the Millennium Development Goals.

The current water utility AdaRM has reinforced the link with the community through the creation since late 2011 of a permanent team from their staff to develop community marketing initiatives in Maxaquene $A$ and Maxaquene $B$, and to continue the job carried out by the $\mathrm{CBO}$ s throughout the program in these suburbs. In parallel with the new payment mechanisms recently established, this has contributed significantly to the successful increase of the uptake of household connections.

\section{Conclusions}

An attempt to scale up a sustainable water scheme to 120,000 residents of peri-urban areas in the city of Maputo through household connections has been assessed. Factors influencing the uptake of water connections in two suburbs of Maputo will inform the plans to extend the scheme to neighbouring areas. 
In Maxaquene $A$ and Maxaquene $B$, the two studied bairros, the access of low income households to private connections had been lower than expected, despite a targeted intervention to increase household connections. The connection costs were not actually too high, however charges could be more affordable for the urban poor in these suburbs if the water utility offered flexible payment options. The study shows that all informants agreed on the need to establish new payment mechanisms to allow connection charges to be spread across a longer period. In parallel, the relationship between the service provider and the urban poor in peri-urban areas of Maputo needed some improvement. This engagement of the water supplier with the residents is key to achieving sustainability of the intervention because it is addressing the real needs of the households. In this way, the demands of the residents are understood more carefully and therefore the beneficiaries trust the proposed intervention. The engagement of the water provider is best achieved through collaboration with community based organisations which acted as the link between the utility and the residents,

Without de-emphasizing the need to improve alternative water sources for the most vulnerable urban poor, there are two key factors outstanding as the lessons learnt in this study. The uptake of household water connections in peri-urban areas of Maputo has been increased by offering flexible payment options to allow spreading the charges into a large number of monthly affordable instalments and by engaging the water provider with the residents through collaboration with community based organizations. These approaches are promising not only for Maputo but also other low-income countries struggling to improve services to the urban poor. Whilst the latter really needs to be the initiative of the utility itself, the former could be instigated by a regulator keen to improve water access by the poorest.

The interface between utility business models and the payment mechanisms which finance investment is an important area of innovation for infrastructure based utility services. The adage that 'there is more than one way to skin a cat' is highly relevant here as methods of billing and paying for services which are well established in one context are unlikely to be acceptable (or even feasible) in another. This challenge is unlikely to become redundant any time soon as the socio-economic reality for both existing and potential utility customers across the globe becomes more heterogeneous over time. The ability to match payment mechanisms to socio-economic circumstances and the ability to pay may well define what a successful utility looks like over the coming years and in this way our findings have wider resonance for utility policy. With levels of customer debt on a seemingly unstoppable rise, utilities in countries with well established infrastructure based services will need to take note of customers' desire for greater choice in how they pay. This might involve flexibility around the timing and proportioning of payments as well as greater levels of service differentiation. The challenge for utilities is to learn to cope with the enhanced uncertainty and risk that can emerge from more flexible payment regimes.

\section{Acknowledgments}

The authors would like to thank Water and Sanitation for the Urban Poor (WSUP) for funding of the work reported above. We would also extend our gratitude to Carla Costa, Artur 
Furtada, Zito Mugabe, Dinis Namburete, Jaime Palanane, R. Shackleton and Jeremie Taillainder for supplying data, sharing knowledge and supporting the project.

\section{References}

Aiga, H., and T. Umenai. 2002. Impact of improvement of water supply on household economy in a squatter area of manila. Social Science \& Medicine 55, : 627.

Allen, A., J. Davila, and P. Hofmann. 2006. The peri-urban water poor: Citizens or consumers? Environment and Urbanization 18, (2): 333.

Banerjee, S., V. Foster, Y. Ying, H. Skilling, and Q. Wodon. 2010. Cost recovery, equity, and efficiency in water tariffs. Africa Region: The World Bank, 5384.

Burra, S. 2005. Towards a pro-poor framework for slum upgrading in Mumbai, India. Environment and Urbanization 17, (1): 67.

Collignon, B., and M. Vezina. 2000. Independent water and sanitation providers in African cities. Water and Sanitation Program, .

Davis, J. 2004. Scaling up urban upgrading: Where are the bottlenecks? International Development Planning Review 26, (3): 305.

DelwarAkbar, H., J. Minnery, B. VanHoren, and P. Smith. 2007. Community water supply for the urban poor in developing countries: The case of Dhaka, Bangladesh. Habitat International 31, : 24.

Ferguson, B., and J. Navarrete. 2003. A financial framework for reducing slums: Lessons from experience in Latin America. Environment and Urbanization 15, (2): 201.

Fernandez-Maldonado, A. M. 2008. Expanding networks for the urban poor: Water and telecommunications services in Lima, Peru. Geoforum 39, : 1884-96.

Gerlach, E., and R. Franceys. 2010. Regulating water services for all in developing economies. World Development.

Gessler, M., U. Brighu, and R. Franceys. 2008. The challenge of economic regulation of water and sanitation in urban India. Habitat International 32, : 49-57.

Goether, R. 2001. The use of IT in scaling up urban slum improvements efforts. Municipal Engineer 145, (4): 285.

Gulyani, S., and E. Basset. 2007. Retrieving the baby from the bathwater: Slum upgrading in Sub-Saharan Africa. Environment and Planning C: Government and Policy 25, (4): 486.

Gulyani, S., D. Talukdar, and D. Jack. 2010. Poverty, living conditions, and infrastructure access. Africa Region: The World Bank, 5388. 
Kayaga, S., J. Calvert, and K. Sansom. 2003. Paying for water services: Effects of household characteristics. Utilities Policy 11, : 123-32.

Kayaga, S., and R. Franceys. 2007. Costs of urban utility water connections: Excessive burden to the poor. Utilities Policy 15, : 270-7.

Keener, S., M. Luengo, and S. Banerjee. 2010. Provision of water to the poor in Africa. Africa Region: The World Bank, 5387.

Khan, S. J., and L. E. Gerrard. 2006. Stakeholder communications for successful water reuse operations. Desalination 187, : 191-202.

Kooy, M., K. Bakker, E. Martijn, and N. E. Shofiani. 2008. Governance failure: Rethinking the institutional dimensions of urban water supply to poor households. World Development 36, (10): 1891-925.

Malizani, I. 2008. The role of stakeholders in the provision and management of water kiosks in Nkolokoti, Blantyre (Malawi). Physics and Chemistry of the Earth 33, : 833.

Mara, D., and G. Alabaster. 2008. A new paradigm for low-cost urban water supplies and sanitation in developing countries. Water Policy 10, : 119.

Marimbe, S., and E. Manzungu. 2003. Challenges of communicating integrated water resource management in Zimbabwe. Physics and Chemistry of the Earth 28, : 1077-84.

Matsinhe, N. P., D. Juizo, L. Rietveld, and K. Persson. 2008. Water services with independent providers in peri-urban Maputo: Challenges and opportunities for long-term development. Water SA 34, (3): 411.

Mugabe, Z., D. Namburete, and J. Palanane. 2011. WSUP practice notes: Helping people connect to water networks: Good for the business, good for the poor?

Ndokosho, J., Z. Hoko, and H. Makurira. 2007. Assessment of management approaches in a public water utility: A case study of the Namibia water corporation (NAMWATER). Physics and Chemistry of the Earth 32, : 1300-9.

Pinera, J. F., and R. Reed. 2009. A tale of two cities: Restoring water services in Kabul and Monrovia. Disasters 33, (4): 574.

Raje, D. V., P. S. Dhobe, and A. W. Deshpande. 2002. Consumer's willingness to pay more for municipal supplied water: A case study. Ecological Economics 42, : 391.

Ravallion, M., and M. Lokshin. 2005. Who cares about relative deprivation? Washington, D.C.: World Bank, Policy Research Working Paper.

UNHabitat. 2010. State of the World's Cities 2010/2011. Bridging the Urban Divide.

UN-Habitat. 2003. Water and sanitation in the world's cities. London: Earthscan.

Van den Boom, B. 2011. Analysis of poverty in Mozambique. Household poverty status, child malnutrition and other indicators 1997, 2003, 2009. Maputo: Royal Dutch Embassy. 
